\title{
BİST'de İşlem Gören Gayrimenkul Yatırım Ortaklığ1 İşletmelerinin Finansal Performanslarının ÇKKV Yöntemleri İle Karşılaştırılması
}

\author{
Umut Tolga GÜMÜŞ ${ }^{1}$, Hatice Can ÖZİÇ ${ }^{2}$ ve Erkan ÇIBIK ${ }^{3}$
}

$\ddot{O} z$

Geleceğimizi öngörebilmek ve günümüz rekabet ortamında şirketlerin finansal performanslarının önemli bir unsur olduğu bilinmektedir. Durum böyle olunca sadece finansal oran analizleri de belli bir ölçüde yeterli gelmediği görülmüştür. Bunun için araştırmacılar belirli yöntemler geliştirmiş ve uygulamalar gerçekleştirmişlerdir. Bu uygulamalar arasında çok kriterli karar verme yöntemleri sıklıkla kullanılan bir yöntemler dizisi olduğu görülmüştür. Türkiye'de gayrimenkul yatırım ortaklığ1 şirketleri de sermayesi ciddi önemli bir sektör olduğu bilinmektedir. Bu yüzdendir ki bu sektörde faaliyet gösteren işletmelerin finansal rasyo analizlerinin yapılması yatırımcılar ve şirket yöneticileri için önemlidir. Bu çalısmamızda gayrimenkul yatırım ortaklığı sektöründe faaliyet gösteren sermayesi en yüksek on şirket ele alınarak belli finansal oranlar ile çok kriterli karar verme yöntemleri olan TOPSIS ile MOORA yöntemi kullanılmıştır. Bu çalışmanın öncelikli amacı, farklı standartlardaki ölçüm araçları ile şirketlerin finansal performans sıralamalarının ölçülmesi amaçlanmışır. Bu çalışmamızda hisse senetleri borsada işlem görmekte olan sermayesi 2017 y1l için en yüksek seviyede olduğu tespit edilen gayrimenkul yatırım ortaklığı şirketlerinin finansal performanslarının sıralaması TOPSIS ve MOORA tekniği kullanılarak yapılmıştır. Çalışmada ilk olarak 2013-2017 yılsonu verileriyle 10 adet geleneksel olarak kullanılan finansal oran hesaplanmış daha sonra oranların ortalaması alınarak TOPSIS ve MOORA yönteminin karar matrisi bu şekilde oluşturulmuştur. Böylelikle kullanılan 10 şirketin oran analizleriyle finansal performans kriterleri açısından oluşturulan sıralamalar karşılaştırılıp yorumlanmışır.

Anabtar Kelimeler: BİST, Finansal Performans, Gayrimenkul Yatırım Ortaklığı, TOPSIS, MORAA

\section{Comparison of the Financial Performances of Real Estate Investment Partnership Companies That Are Operated in BIST}

\begin{abstract}
It is known that the financial performance of the companies is an important factor in predicting our future and in today's competitive environment. As a result, only financial ratio analyzes were not sufficient to a certain extent. To this end, researchers have developed and implemented specific methods. Among these applications, multi-criteria decision-making methods are frequently used. Real estate investment in Turkey which is also known to have serious capital is an important sector. Therefore, the financial ratio analysis of the enterprises operating in this sector is important for investors and company managers. In this study, TOPSIS and MOORA method, which are multi-criteria decision-making methods, were used by taking into account the highest financial ratios and the ten highest companies operating in the real estate investment trust sector. The primary objective of this study is to measure the financial performance ranking of companies with measurement instruments of different standards. In this study, the financial performances of real estate investment trust companies, whose shares are traded on the stock exchange, are determined to be at the highest level in 2017 by using TOPSIS and MOORA technique. In the study, 10 traditionally used financial ratios were calculated with the end of 20132017 year-end data and then the decision matrix of TOPSIS and MOORA method was created by taking the average of the rates. Thus, the rankings of 10 companies were compared and interpreted in terms of financial performance criteria.
\end{abstract}

Key Words: BIST, Financial Performance, Real Estate Investment Trust, TOPSIS, MORAA

\section{Atıf İçin / Please Cite As:}

Gümüş, U. T., Can-Öziç, H. ve Çıbık, E. (2020). BİST’de işlem gören gayrimenkul yatırım ortaklığı işletmelerinin finansal performanslarının ÇKKV yöntemleri ile karşılaştırılması. Manas Sosyal Araştırmalar Dergisi, 9(1), 90-100.

\footnotetext{
${ }^{1}$ Dr. Öğrt. Üyesi - Türkiye - Adnan Menderes Üniversitesi, Nazilli İktisadi ve İdari Bilimler Fakültesi, ugumus@adu.edu.tr ORCID: 0000-0001-7363-8660

2 Doktora Öğrencisi - Türkiye- Adnan Menderes Üniversitesi, Söke İşletme Fakültesi, haticecan88@gmail.com ORCID: 0000-0002-8380-4607

3 Yüksek Lisans Öğrencisi - Adnan Menderes Üniversitesi, Sosyal Bilimler, Sosyal Bilimler Enstitüsü, erkancibik16@gmail.com ORCID: 0000-0002-3688-6291
} 


\section{Giriş}

İşetmelerin finansal performanslarını ölçmek firma yöneticileri, yatırımcılar, firmalara finansal kredi sağlayan aracı kurumlar açısından önemli olduğu bilinmektedir. Haliyle finansal performans ölçümleri için genellikle oran analizleri ve bu analizlerin karşılaştırılması kullanılmaktadır. Fakat belli bir ölçü çerçevesinde dinamik bazı göstergeleri dikkate almayan rasyo analizleri belirli ölçüde zamanla yetersiz geldiği görülmüştür. Bunun için çeşitli uygulamalar geliştirilmiş ve rasyo analizlerinin dışında bazı uygulamalar kullanılarak işletmelerin finansal performansları ölçülmeye çalışılmıştır. Bu uygulamalardan en çok kullanılanları çok kriterli karar verme metotları olan AHP, TOPSIS, ELECTRE, MOORA yöntemleridir.

Günümüz firmaları için en önemli unsurlardan bir tanesinin verileriyle karar verme sürecinde uygun ve en iyi karar1 vermesi olduğu bilinmektedir. İşletmeler ve yatırımcılar belirli dönemlerde kendi finansal performanslarını görmek, yatırımcılar da yatırım olanakları arasında karar alabilmeleri için zaman zaman finansal performans ölçüm araçlarından yararlanmaktadırlar. Bu araçlardan en önemlilerinden bir tanesi literatürde de genellikle kullanılan alternatifler arasında tercih yapmaya olanak taniyan TOPSIS yöntemidir. TOPSIS belirli kriterlerde alternatifler arasında sıralama yapabilen çok kriterli karar verme yöntemlerinden birisidir. Karar verme aşamasında belirli kriterler kullanılırken bazı kriterler göz ardı edilebilmektedir. Çok kriterli karar verme yöntemleri kriterlere önem dereceleri verebildiği için homojen bir dağllım ile alternatiflerden en uygununu seçmeye olanak tanımaktadır. Literatüre bakıldığı zaman ise çok kriterli karar verme yöntemleri olan AHP, TOPSIS, MOORA ve ELECTRE yöntemleri sıklıkla kullanıldı̆̆1 görülmektedir. $\mathrm{Bu}$ yöntemler sadece bir finansal performans ölçüm araçlarında değil birçok alanda alternatifler arasında seçim yapmaya olanak tanıdığı görülmektedir. Bu çalışmada ise karar verici uygulamalar olarak TOPSIS ve MOORA yöntemleri kullanılarak karşılaştırılmalar yapılmıştır.

Bu çalışmamızda hisseleri Borsa İstanbul'da işlem gören gayrimenkul yatırım ortaklı̆̆ sektöründe faaliyet gösteren sermayesi 2017 yllı verisine göre en yüksek olarak tespit edilen 15 şirket arasından verileri düzenli olarak görülmüş 10 şirket belirlenerek analizler gerçekleștirilmiştir. Verileri düzenli olarak tespit edilen bu 10 GYO işletmesinin 2013-2017 son dönem finansal tabloları ile geleneksel olarak kullanılan 10 adet finansal rasyo oranı Excel paket programı ile hesaplanmış daha sonra bu 5 yıllık verilerin ortalaması alınarak çok kriterli karar verme yöntemleri olan TOPSIS ve MOORA teknikleri için karar matrisi bu şekilde oluşturulmuştur.

Bu çalışmada yukarıda belirtilen sermayesi en yüksek gayrimenkul yatırım ortaklı̆ğ firmasıyla 20132017 yılı finansal tabloları kullanılarak belirli oran analizleri yapılmıss. Daha sonra bir performans ölçüm sıralaması oluşturabilmek adına çok kriterli karar verme yöntemleri olan TOPSIS ve MOORA yöntemleri uygulanarak sıralamalar belirlenmiştir. Bu sıralama sonuçları kapsamında şirketler arasında finansal performans yorumları yapılmaya çalışılmıştır. Ayrıca bu iki yöntem arasındaki ve MOORA yönteminde kullanılan 4 ana yaklaşım arasında uygulanan yöntemler arasındaki sıralama sonuçlarının uyumluluğu tartışılmıştır. Sonuç olarak belirli analizler sonucunda çıkan sonuçlar ve veriler literatür kapsamında yorumlanmış analiz sonuçları ortaya konulmuştur.

\section{Yöntem}

\section{TOPSIS Yöntemi}

Günlük hayatta birçok yerde ve birçok alanda insanlar ve şirketler belirli şeylerin en iyi şekilde kararlarını vermeye çalışıyorlar. Karşı karşıya kalınan duruma göre genellikle kazancımızı maksimize, kaybımızı ise minimize etmeye çalışırız. Her gün verdiğimiz bu kararlar neticesinde alternatifler arasından bizim için optimum faydayı sağlayabilecek alternatifi seçmeye çalışırız. Bunun için karar vermede kullanılabilecek en etkili yöntemlerden bir tanesi TOPSIS yöntemidir. Bu teknik çeşitli alternatifler arsından belirli kriterler ile en uygun alternatifi seçmeye olanak tanıyan bir yöntemdir.( Özdemir, 2015, s. 133,134).

TOPSIS, kısacası pozitif ideal çözüme göreli olarak en yakın olan ve negatif ideal çözüme ise uzak olan alternatifi bulmaya yarayan bir yaklaşımdır.(Qin et al., 2008, s. 2166). TOPSİS, tedarik zinciri yönetimi, tasarım, üretim sistemleri, işletme yönetimi, pazarlama ve insan kaynakları yönetimi, finans, depo seçimi ve yönetimi, personel seçimi ve yönetimi gibi daha birçok alanda yaygın olarak kullanılabilen bir analiz tekniğidir.(Velasquez and Hester, 2013, s. 62-63). TOPSIS analizinde performans derecelendirmeleri ve kriter ağırlıkları başarılı bir şekilde belirlenebilmektedir. 
TOPSIS, 1981 yilında Hwang ve Yoon tarafindan geliştirilmiş çok kriterli karar verme metodlarından birisidir ( Pawlakk, 1982, s. 341). TOPSIS kelimesi, Technique for Order Preference by Similarity to Ideal Solutions kelimelerinin baş harflerinden oluşmaktadır.

TOPSIS yöntemi diğer birçok yöntem gibi karmaşık matematiksel işlemler içermeyen anlaşılmasının kolay olduğu ve yorumlanmasında zorluk yaşanmaması sebebiyle sıklikla birçok alanda kullanilabilmektedir.( Blanszcynski, 2007, s. 1030-1044).

TOPSIS Tekniği ile alternatiflerin belirli kriterler doğrultusunda sıralanması yapılabilmektedir. Bu yöntem 6 aşamadan oluşan bir dizi formuliszasyon yardımı ile yapılan bir yöntemdir. Bu tekniğin ilk aşamasını karar matrisinin oluşturulması aşaması oluşturmaktadır. Karar matrisi alternatifleri sıralanmak istenen ögeler satırlara ve bu alternatifler arasından seçim yapmaya olanak tanıyan kriterler sütunlara gelecek şekilde oluşturulur. Karar matrisi ile alternatifler ve kriterler belirlendikten sonra karar matrisinden hareket ile normalize edilmiş karar matrisi elde edilir. Normalizasyon işleminin yapılma sebebi farklı birimlerde ve farklı boyutlarda olan kriterleri belirli bir düzeye yaklaştırmak ve birim faktörünü ortadan kaldırmak için yapılmaktadır. Normalize edilmiş karar matrisinden sonra her bir kriter için ağırlık dereceleri ve alternatiflerin seçiminde optimize olması için minimum maksimum değerleri belirlenir. Belirlenen ağırlık dereceleri ile normalize matris değerleri çarpılarak Ağırlıklandırılmış normalize matris oluşturulur. Daha sonra bu matristen yola çıkılarak maksimum ve minimum olarak belirlenen kriterler ile ideal çözüme ve negatif ideal çözüme uzaklık değerleri hesaplanır. Son aşama olarak ise negatif ve pozitif uzaklık değerleri dikkate alınarak göreceli puanlar hesaplanır ve alternatiflerin sıralaması puanı en büyük olan ilk sırada yer alacak şekilde sıralaması yapıllır. Sıralama neticesinde en iyi alternatifler ve en kötü alternatifler belirlenmiş olur. (Blanszcynski, 2013, s. 1030).

Bu çalışmada TOPSIS yönteminin aşamaları bu kadar anlatılmıştır. TOPSIS yönteminin formüllerine ve uygulama aşamalarını incelemek için 2017 yllı Borsa'da İşlem Gören Gayrimenkul Yatırım Ortaklığ1 Şirketlerinin Finansal Performanslarının Karşılaştırılması: Bist'de TOPSIS Uygulama isimli makalemizi inceleyebilirsiniz.

\section{MORAA Yöntemi}

Multi-Objective Optimization by Ratio Analysis kısacası MOORA yöntemi ilk olarak Brauers ve Zavadskas tarafindan geliştirilmiştir. Çok faktörlü karar verme yöntemlerinden biri olan MOORA yeni bir yöntem olup birçok alanda kullanılmıştır. Literatürde yer alan karar verme uygulamalarına destek olmak amacı ile farklı uygulamalar geliştirme ile oluşturulan bir yöntemdir. (Brauers ve Zavadskas, 2006)

Yeni gelişmekte olan bir yöntem olup literatürde MOORA Oran Metodu, MOORA-Referans Noktası Yaklaşımı, MOORA-Önem Katsayısı, MOORA Tam Çarpım yaklaşımı ve MULTI-MOORA adında farklı yaklaşım türleri yer almaktadır. ( Ersöz ve Atav, 2011, s. 79)

Bazı kaynaklarda MOORA yöntemi çoğunlukla oran metodu ve referans nokta yaklaşımları ile hesaplanmakta, bazı kaynaklarda ise yöntemlerin hepsi kullanılarak sıralamalar yapılabilmektedir. Bizim çalışmamızda MOORA yöntemi ile ilgili 4 yaklaşım uygulanmıştır. Bu yaklaşımların nasıl yapıldığı aşağıda anlatılmaktadır. Yöntem alternatiflerin ve kriterlerin belirlenip matris şeklinde oluşturulması ile başlar ve aşağıdaki gibi devam eder.

\section{MOORA-Oran Metodu}

Karar matrisi karar vericinin oluşturmas1 gereken bir matris olup $m \times n$ boyutlu bir matris olması gerekmektedir. Karar verici karar matrisinin satırlarında sıralanacak alternatiflere ( karar noktaları), sütunlarında ise karar vermede kullanılan değerlendirme kriterleri ( faktörlere) yer vermelidir.

$$
X_{i j}=\left[\begin{array}{ccc}
x_{11} & x_{12} \ldots & x_{1 n} \\
x_{21} & x_{22} \ldots & x_{2 n} \\
\vdots & \vdots & \vdots \\
x_{\mathrm{m} 1} & x_{\mathrm{m} 2} & x_{\mathrm{mn}}
\end{array}\right]
$$

Burada $\mathrm{m}$ karar matrisinde derecelendirilecek alternatiflerin( karar noktalarının) sayısını $(\mathrm{i}=1, \ldots \mathrm{m}), \mathrm{n}$ ise değerlendirme kriteri(faktörü) sayısını $(\mathrm{j}=1, \ldots, \mathrm{n})$ ifade etmektedir. Bu şekilde karar matrisi oluşturulduktan sonra bu karar matrisi kullanılarak normalize matrisin oluşturulması aşamasına geçilir. $\mathrm{Bu}$ işlem; 


$$
X_{i j}^{*}=\frac{x_{i j}^{*}}{\sqrt{\sum_{i=1}^{m} x_{i j}^{2}}}
$$

Genellikle $X_{i j}^{*} \in[0,1] \quad$ dir. Bazı durumlarda $\quad X_{i j}^{*} * \in[-1,1]$ Olabilmektedir. (Önay ve Çetin, 2012, s. 94).

Karar matrisinin normalize edilmesi şu açıdan önemlidir. Alternatifler ve kriterler arasındaki her bir değer bir birinden farklı uç değerler olabilir hatta bu değerlerin birimleri bile bir birinden farklı olabilir. Normalize matris oluşturularak her bir değer ağırlıkları ölçüsünde ölçüm için bir birine yaklaştırılır. Böylelikle birbirine yakın değerler oluşturulmuş olur. Aradaki varsa birim faktörü ortadan kaldırılmış olur.

$\mathrm{Bu}$ normalizasyon işleminden sonra hazırlanan yeni matriste kriterlerin maksimum veya minimum olmasına göre belirlenip, toplanırlar ve toplanan maksimum kriterlerin değerinden minimum kriterlerin değeri çıkartılarak sonuçlar elde edilir. Yani $j=1,2, \ldots, g$ maksimize edilecek kriterler, $j=g+1, g+2, \ldots, n$ minimize edilecek kriterler olmak üzere formül şu şekildedir. (Brauers ve Ginevicius 2009: s.123)

$$
Y_{i}^{*}=\sum_{j=1}^{g} x_{i j}^{*}-\sum_{j=g+1}^{n} x_{i j}^{*}
$$

Bu formül sonucu ile $Y_{i}^{*}$ değerlerinin büyükten küçüğe sıralanması ile işlem tamamlanmış olur. (Önay ve Çetin 2012: s.94).

\section{MOORA-Referans Nokta Yaklaşımı}

$\mathrm{Bu}$ yaklaşımda ise MOORA oran yöntemi ile elde edilen normalize edilmiş matris ele alınarak işlem yapılır. Referans noktası yaklaşımında alternatifler arasında belirlenen kriterlerin maksimizasyon için en büyük değeri, minimizasyon için ise en küçük değeri referans olarak alınır. Daha sonra aşağıdaki formül kullanılarak kriterlerin her birinin referans noktasına olan uzaklıkları hesaplanır.

$$
d_{i j=}\left|r_{i}-x_{i j}^{*}\right|
$$

Son olarak alternatiflerin sıralanması aşamasına gelinir. Alternatiflerin sıralanması için ise her bir alternatifin en yüksek değeri bulunur. Alternatifler küçükten büyüğe doğru sıralanır. Birinci sıradaki alternatif en iyi seçenek olarak kabul edilmektedir (Brauers ve Zavadskas, 2006, s. 448).

$$
p_{i=} \min _{i}\left(\max _{j} d_{i j}\right)
$$

MOORA- Önem Katsayısı Yaklaşımı

$\mathrm{Bu}$ yöntemde de MOORA oran metodu ile elde edilmiş olan normalize matris dikkate alınarak hesaplamalar yapılmaktadır. Kriterler belirlenirken bazı durumlarda kriterlerin öncelikleri bir birinden farklı olabilmektedir. Kriterlerin öncelikleri dikkate alındığ1 zaman alternatiflerin sıralanması için performans değerleri şu formül ile hesaplanmaktadır. (Stanujkic vd., 2012, s. 337).

$$
Y_{i}^{*}=\sum_{j=1}^{g} w_{j} x_{i j}^{*}-\sum_{j=g+1}^{n} w_{j} x_{i j}^{*}
$$

$w_{j}$ Burada kriterlerin önemlilik derecelerini yani ağırlıklarını göstermektedir.

Kriterlerin belirlenen önem ağırlıklarının referans noktası yaklaşımında da kullanılması etkili sonuçlar elde etmek amacı ile iyi bir yoldur. $Y_{i}^{*}$ Değerleri büyükten küçüğe sıralanarak birinci sıradaki alternatif en uygun alternatif olarak belirlenir (Stanujkic vd., 2012, s. 337).

MOORA- Tam Çarpım Yaklaşımı 
$\mathrm{Bu}$ yaklaşım 2010 yılında geliştirilen yeni bir yaklaşımdır. Bu yöntemde her bir alternatifin maksimizasyon amaçlı verileri çarpılarak minimizasyon amaçlı verilerin çarpımına bölünür. Bu yaklaşımın formülü şu şekilde tarif edilebilir.

$U_{i}^{*}=\frac{A_{i}}{B_{i}}$

Burada;

$$
A_{i}=\prod_{g=1}^{j} x_{g j}
$$

$i=1, \ldots, m ; m$, alternatiflerin sayısını, $j$ ise maksimizasyon yapılan kriterlerin sayısını göstermektedir.

$$
B_{i}=\prod_{k=j+1}^{n} x_{k j}
$$

$n=j$ minimizasyon kriterlerinin sayısını göstermektedir. $U_{i}^{*}$ burada alternatiflerin puanlarını gösterir. Böylelikle bu puanlar büyükten küçüğe sıralanarak birinci sıradaki alternatif en uygun alternatif olarak belirlenir.

MULTIMOORA yaklaşımı

MULTIMOORA yaklaşımı da tam çarpım yaklaşımı ile MOORA yöntemlerinin bir özeti şeklinde yapılan bir yöntemdir. Bu yöntemde ise temel amaç kriterler arasında öncelikli seçenekleri belirleyerek karar vericiye yardımcı olmaktır.

\section{Evren - Örneklem}

Araştırmanın evren ve örneklemi kapsamında belirlenen şirketler ve kullanılan finansal oranlar şu şekilde tespit edilmiştir.2017 yılında yılsonu finansal tabloları kullanılarak yapılan analizler doğrultusunda BİST'de verileri süreklilik arz eden 10 adet Gayrimenkul yatırım ortaklığı firması tespit edilmiştir. Bu firmalar Tablo 1'de gösterilmiştir.

Tablo 1. Calisma Kapsamında Yer Alan İsletmeler ve BİST Kodlar

\begin{tabular}{lll}
\hline SIRA & BİST KODU & ŞİRKET ÜNVANI \\
\hline 1 & AKFGY & AKFEN GYO \\
2 & AKSGY & AKIŞ GYO \\
3 & EKGYO & EMLAK KONUT GYO \\
4 & HLGYO & HALK GYO \\
5 & ISGYO & ISS GYO \\
6 & KLILER GYO \\
7 & OZKGY & ÖZAK GYO \\
8 & RYGYO & REYSAŞ GYO \\
9 & SNGYO & SİNPAŞ GYO \\
10 & TRGYO & TORUNLAR GYO \\
\hline
\end{tabular}

TOPSIS ve MOORA yöntemi kullanılarak yapılan analizler sonucu için elde edilen veriler kamuyu aydınlatma platformundan (KAP) şirketlerin finansal tabloları alınarak sağlanmıştır. Finansal oranların hesaplanması ve uygulamaların kullanılması Microsoft Excel paket programı kullanılarak yapılmıştır. TOPSIS ve MOORA teknikleri için firmaların finansal tablolarındaki veriler ile 10 adet finansal oran hesaplanmıştır. Çalışmada kullanılan finansal oranlar Tablo 2'de gösterilmiştir. 
Tablo 2. Calısmada Kullanilan Finansal Oranlar

\begin{tabular}{llll}
\hline NO & FİNANSAL ORAN KODU & FİNANSAL ORANLAR & \\
\hline 1 & FO1 & Cari Oran & Dönen Varlıklar/Kısa Vadeli Yabancı Kaynaklar \\
2 & FO2 & Nakit Oranı & Hazır Değerler+ Menkul Kiymetler/ KVYK \\
3 & FO3 & Aktif Devir Hız1 & Net Satışlar / Toplam Aktifler \\
4 & FO4 & Alacak Devir Hız1 & Net Satıslar / Ticari Alacaklar \\
5 & FO5 & Net Çalışma Sermayesi D.H. & Net Satışlar/(Dönen V.-KVYK) \\
6 & FO6 & Finansman Oranı & Öz kaynaklar/ UVYK+KVYK \\
7 & FO7 & Finansal Kaldıraç & (UVYK+KVYK)/Toplam Aktifler \\
8 & FO8 & Net Kar Marjı & Net Kar / Net Satışlar \\
9 & FO9 & Öz Sermaye Karlıı̆ı̆1 & Net Kar / Öz Kaynaklar \\
10 & FO10 & Aktif Karlılık & Net Kar / Toplam Aktifler \\
\hline
\end{tabular}

\section{Veri Toplama Araçları}

Bu çalışmada BİST’de işlem gören gayrimenkul yatırım ortaklı̆̆ı sektöründeki sermayesi 2017 yllında en yüksek olarak tespit edilen ve verileri, oran analizleri düzenli olan 10 adet firmanın çok kriterli karar verme yöntemlerinden olan TOPSIS ve MOORA teknikleri ile finansal performanslarının ölçülmesi, karşılaştırmaların yapılması ve sıralanması amaçlanmıştır. Bu çalışma kapsamında performans ölçümleri için kriter olarak 10 adet finansal rasyo oranı kullanılmışır.

İşletmelerin verileri ve finansal performanslarının hesaplanması için bilanço ve gelir tablosu kalemleri Kamuyu Aydınlatma Platformunun (KAP) sitesinden elde edilmiştir. Buradan yararlanılan veriler ile işletmelerin finansal performansları için oran analizleri yapılmıştır. Oran analizlerinin ve uygulamaların yapılması için Excel Office paket programı kullanılmıştır.

\section{Verilerin Analizi}

Araştırmanın veri toplama araçları ile elde edilen finansal oranlar ve diğer veriler Excel yardımı ile TOPSIS ve MOORA yöntemlerinin metotları uygulanarak analiz edilmiştir. Yöntemler ile oluşturulan sıralama sonuçları incelenerek yöntemlerin bir birine uyumlulukları incelenmiştir.

\section{Bulgular}

Çok kriterli karar verme yöntemlerinden olan TOPSIS ve MOORA yöntemleri ile analizler yapılmaya başlandığı zaman ilk işlem alternatiflerin ve kriterlerin belirlenmesi ile karar matrisinin oluşturulması olacaktır. Bizim bu çalısmamızda alternatifler Gyo firmaları olurken kriterlerimiz ise belirli geleneksel olarak kullanılan finansal oranlardır. Bu çalışmada 10 adet işletme ve 10 adet finansal oran kullanıldığı için çalışmanın karar matrisi de $10 * 10$ boyutlu bir matris olacaktır. Yapılan analizlerde kullanılmak üzere oluşturulan karar matrisi Tablo 3'de gösterilmiştir. Yapılan TOPSIS ve MOORA analizleri Tablo 3'de yer alan veriler ışı̆̆ında gerçekleştirilmiştir.

Tablo 3. GYO Karar Matrisi (A)

\begin{tabular}{|c|c|c|c|c|c|c|c|c|c|c|}
\hline & K1 & K2 & K3 & K4 & K5 & K6 & K7 & K8 & K9 & K10 \\
\hline AKFGY & 0,30531 & 0,16153 & 0,02681 & 4,04632 & $-0,6730$ & 1,15443 & 0,47684 & $-1,8127$ & $-0,1003$ & $-0,0407$ \\
\hline AKSGY & 0,58521 & 0,14846 & 0,05630 & 4,29007 & 0,19309 & 1,45388 & 0,40785 & 1,64063 & 0,14450 & 0,08537 \\
\hline EKGYO & 1,98078 & 0,47871 & 0,15488 & 1,12124 & $-1,0238$ & 1,43515 & 0,41186 & 0,49537 & 0,12864 & 0,07576 \\
\hline HLGYO & 1,83464 & 0,32372 & 0,05966 & 3,71416 & 0,67733 & 8,43732 & 0,12522 & 1,54034 & 0,08962 & 0,07822 \\
\hline ISGYO & 1,76799 & 0,69297 & 0,10445 & 8,52799 & 2,36751 & 2,25593 & 0,31783 & 1,13378 & 0,12657 & 0,08744 \\
\hline KLGYO & 1,56790 & 0,12321 & 0,09062 & 0,80978 & 0,86935 & 1,26864 & 0,44903 & 0,80783 & 0,06984 & 0,04109 \\
\hline OZKGY & 0,71393 & 0,37565 & 0,09660 & 21,02921 & $-0,7774$ & 1,68399 & 0,38093 & 1,42768 & 0,14480 & 0,09101 \\
\hline RYGYO & 1,19741 & 0,63068 & 0,07249 & 2,61692 & 3,01704 & 1,28293 & 0,44828 & 1,03633 & 0,11478 & 0,06268 \\
\hline SNGYO & 2,16067 & 0,13934 & 0,24765 & 1,58421 & 0,95711 & 0,99091 & 0,50862 & $-0,0841$ & $-0,0272$ & $-0,0106$ \\
\hline TRGYO & 1,38618 & 0,64206 & 0,07294 & 3,28323 & 0,76768 & 1,19013 & 0,45929 & 1,15708 & 0,15898 & 0,08736 \\
\hline
\end{tabular}


Karar matrisi oluşturulduktan sonra hem TOPSIS yönteminde hem de MOORA yönteminde kullanılmak üzere karar matrisi normalize matris şekline dönüştürülmesi gerekmektedir. Bunun için ise formül gereği her bir sütundaki değerlerin kareleri toplamının kareköküne bölünmesi ile gerçekleştirilmektedir. Normalize edilmiş matris formatına Excel ortamında matematiksel işlem olan top karekök işlemi ile kolay yoldan yapılabilmektedir. Karar matrisinin normalizasyon işlemi önemlidir. Çünkü bu işlem ile veriler belli bir standartta bir birlerine yaklaştırılırlar. Veriler arasındaki varsa birim faktörü ortadan kalmış olur. Bu işlemlerin ardından normalize edilmiş karar matrisi tablo 4'de gösterilmektedir.

Tablo 3'de görüldüğü gibi bazı şirketlerin bazı oranlarının negatif sonuçlarda çıktığ1 görülmektedir. Bu o şirketler için olumsuz olmasına rağmen TOPSIS ve MOORA sonuçlarını etkileyecek bir durum teşkil etmemektedir.

Tablo 4. Normalize Edilmis Karar Matrisi (R)

\begin{tabular}{lcccccccccc}
\hline & $\mathbf{K 1}$ & $\mathbf{K} 2$ & $\mathbf{K 3}$ & $\mathbf{K 4}$ & $\mathbf{K 5}$ & $\mathbf{K 6}$ & $\mathbf{K} 7$ & $\mathbf{K 8}$ & $\mathbf{K 9}$ & $\mathbf{K 1 0}$ \\
\hline AKFGY & 0,06533 & 0,11882 & 0,07386 & 0,16721 & $-0,1521$ & 0,1215 & 0,366 & $-0,4682$ & $-0,2716$ & $-0,1819$ \\
AKSGY & 0,12521 & 0,10921 & 0,15509 & 0,17729 & 0,04365 & 0,15302 & 0,31305 & 0,42372 & 0,39098 & 0,38143 \\
EKGYO & 0,42382 & 0,35215 & 0,42663 & 0,04633 & $-0,2314$ & 0,15105 & 0,31612 & 0,12794 & 0,34806 & 0,33849 \\
HLGYO & 0,39255 & 0,23813 & 0,16433 & 0,15349 & 0,15311 & 0,88802 & 0,09611 & 0,39782 & 0,24248 & 0,34948 \\
ISGYO & 0,37829 & 0,50975 & 0,28772 & 0,35242 & 0,53517 & 0,23744 & 0,24395 & 0,29282 & 0,34247 & 0,39068 \\
KLGYO & 0,33548 & 0,09064 & 0,24961 & 0,03346 & 0,19651 & 0,13352 & 0,34466 & 0,20864 & 0,18898 & 0,18358 \\
OZKGY & 0,15276 & 0,27633 & 0,26608 & 0,86902 & $-0,1757$ & 0,17724 & 0,29239 & 0,36872 & 0,39179 & 0,40665 \\
RYGYO & 0,25621 & 0,46394 & 0,19969 & 0,10814 & 0,68199 & 0,13503 & 0,34408 & 0,26765 & 0,31058 & 0,28003 \\
SNGYO & 0,46231 & 0,1025 & 0,68216 & 0,06547 & 0,21635 & 0,10429 & 0,3904 & $-0,0217$ & $-0,0737$ & $-0,0475$ \\
TRGYO & 0,2966 & 0,47231 & 0,20093 & 0,13568 & 0,17353 & 0,12526 & 0,35253 & 0,29884 & 0,43016 & 0,39031 \\
\hline
\end{tabular}

$\mathrm{Bu}$ aşamadan sonra TOPSIS ve MOORA yöntemlerinde kullanılabilmesi adına kriterlere önem dereceleri ve ağırlıklar verilmesi gerekmektedir. Ağırlıkları belirlemenin birçok metodu vardır. Bizim bu çalışmamızda ağırlıklar eşit olacak şekilde belirlenmesi uygun görülmüştür. Bu ölçüde belirlenen her bir kritere 0,1 ağırlı̆̆ı verilerek ağırlıkların toplamının 1'e eşit olması sağlanmıştır. Ayrıca TOPSIS ve MOORA yöntemlerini uygulayabilmek adına kriterlere maksimum minimum olacak kriterleri belirlemek gerekmektedir. Bunun için yapılan araştırmalar sonucunda nakit oranı, aktif devir hızı, alacak devir hızı, net çalışma sermayesi devir hızı ve aktif karlılık oranları minimum olarak belirlenmiş. Geriye kalan cari oran, finansman oranı, finansal kaldıraç oranı, net kar marjı ve öz sermaye karlılı̆̆ı oranları maksimum olarak belirlenerek çalışma gerçekleştirilmiştir.

MOORA ve TOPSIS yöntemlerinin gerekli formüller ile uygulanması sonucunda aşağıdaki tablo 5'de sonuçlar ve sıralamalanı gösterilmiştir. MOORA yönteminde yer alan 4 yaklaşım kullanılmıştır. Bu kullanılan 4 yaklaşımın sıralama sonuçları ve TOPSIS sonuçları karşılaştırılarak yorumlamalar yapılmıştır.

MOORA yöntemi TOPSIS yöntemine nazaran anlaşılması ve uygulanması kolay bir yöntemdir. Matematiksel formüller yardımıyla Excel paket programı kullanılarak işlemler ve sıralamalar gerçekleştirilir. TOPSIS yönteminden Ağırlıklandırılmış matris oluşturulduktan sonra Maksimum minimum kriterlerine göre negatif uzaklık değerleri ile pozitif uzaklık değerleri belirlendikten sonra alternatifler arasinda seçim yapılabilmesi için göreli uzaklıklar bir birleri ile Oranlanır ve bu değerler 1şığında büyükten küçüğe sıralanarak en büyük değer ilk sırada olacak şekilde sıralanır. Bütün metot ve yöntemler ile uygulanan sıralama sonuçları tablo 5'de gösterilmektedir. 
Tablo 5. GYO MOORA Ve TOPSIS Sonuçar

\begin{tabular}{|c|c|c|c|c|c|c|c|c|c|c|}
\hline ŞİRKETLER & $\begin{array}{l}\text { Oran } \\
\text { Metodu }\end{array}$ & & $\begin{array}{l}\text { Referans } \\
\text { Nokta } \\
\text { Metodu }\end{array}$ & & $\begin{array}{l}\text { Önem } \\
\text { Katsayıs1 } \\
\text { Metodu }\end{array}$ & & $\begin{array}{l}\text { Tam Çarpım } \\
\text { Metodu }\end{array}$ & & $\begin{array}{l}\text { Topsis } \\
\text { Sonuçlar }\end{array}$ & \\
\hline AKFEN GYO & $-0,21283$ & 7 & 0,891898 & 9 & $-0,0212831$ & 7 & 63,69463 & 4 & 0,504296694 & 8 \\
\hline AKİŞ GYO & 0,539323 & 2 & 0,735004 & 2 & 0,05393227 & 2 & 139,1723 & 2 & 0,608431664 & 2 \\
\hline $\begin{array}{l}\text { EMLAK KONUT } \\
\text { GYO }\end{array}$ & 0,434834 & 4 & 0,736976 & 3 & 0,04348338 & 4 & $-11,5697$ & 10 & 0,601486142 & 3 \\
\hline HALK GYO & 0,958462 & 1 & 0,53136 & 1 & 0,09584617 & 1 & 70,41092 & 3 & 0,685980604 & 1 \\
\hline İŞ GYO & $-0,58077$ & 10 & 0,76661 & 6 & $-0,058077$ & 10 & 1,423577 & 7 & 0,486371289 & 10 \\
\hline KIILER GYO & 0,457467 & 3 & 0,754501 & 4 & 0,04574672 & 3 & 156,0381 & 1 & 0,589980884 & 4 \\
\hline ÖZAK GYO & $-0,25946$ & 8 & 0,835559 & 8 & $-0,025946$ & 8 & $-1,75352$ & 8 & 0,527145036 & 6 \\
\hline REYSAŞ GYO & $-0,42026$ & 9 & 0,913435 & 10 & $-0,0420257$ & 9 & 3,620641 & 6 & 0,496613574 & 9 \\
\hline SİNPAŞ GYO & $-0,15743$ & 6 & 0,783732 & 7 & $-0,0157427$ & 6 & $-4,48853$ & 9 & 0,50451947 & 7 \\
\hline $\begin{array}{l}\text { TORUNLAR } \\
\text { GYO }\end{array}$ & 0,130623 & 5 & 0,762764 & 5 & 0,0130623 & 5 & 13,51608 & 5 & 0,568000798 & 5 \\
\hline
\end{tabular}

GYO firmaları ile yapılan TOPSIS ve MOORA yönteminin sonuçları göre tablo 5'e bakılacak olursa finansal performans açısından belirlenen kriterlerde ilk sırada yer alan işletmenin Halk Gyo firması olduğu görülmektedir. Halk Gyo firması uygulanan 5 yöntemin 4'ünde ilk sırada yer almıştır. Sadece tam çarpım metodunda 3 sırada yer aldığı görülmektedir. Analiz sonuçları neticesinde uygulanan bütün yöntemlerde ikinci sırada yer alan işletmenin Akiş Gyo firması olduğu görülmektedir. Bu sonuçlar ile uygulamaların bir birleri ile uyumlu çalıştıkları ve güvenilir oldukları sonucu çıkartılabilir. Uygulama sonuçları neticesinde üçüncü sırada yer alan işletmelerin farklılık gösterdiği tespit edilmiştir. Kiler Gyo işletmesi oran metodu ve önem katsayısı metodunda üçüncü sırada yer alırken, Emlak konut Gyo firması TOPSIS ve referans nokta metodunda üçüncü sırada yer aldığı görülmüştür. Halk Gyo firmasının da tam çarpım metodunda üçüncü sırada yer aldığı tespit edilmiştir.

Firmalar ile yapılan TOPSIS ve MOORA analizleri sonuçları ile son sıralarda yer alan işletmeler farklılık gösterdiği tespit edilmiştir. Fakat İş Gyo firmasının uygulanan 5 yöntemin üçünde son sırada yer alması dikkat çekmektedir. İş Gyo firması Oran metodu, önem katsayısı metodu ve TOPSIS uygulamasında son sırada yer aldığı görülmektedir. Aynı şekilde Reysaş Gyo işletmesinin de uygulanan 4 metot da son sırada yer aldığı tespit edilmiştir. Özak Gyo firmasının da uygulanan 5 metodun 4'ünde sekizinci sırada yer alması dikkat çekmektedir.

Sonuç olarak yöntemler arasındaki uyum dikkat çekmekte ve uygulanan metotların güvenilir oldukları sonucunu ortaya çıkarmıştır. Uygulamalar neticesinde finansal performans açısından iyi durumda ve kötü performans sergileyen işletmeler tespit edilmiştir.

\section{Tartışma, Sonuç ve Öneriler}

Günümüz rekabet ortamında gayrimenkul yatırım ortaklığ1 sektörü, gelişen dünya ekonomisine ayak uydurabilmek adına sürekli gelişme gösteren, gün geçtikçe gelişen teknoloji ile yeniliklere açık bir sektör olduğu ve aynı zamanda dünyada ve ülkemizde birçok iş gücü istihdamı sağlayan bir sektör olduğu bilinmektedir. Bu sebeptendir ki sektörde yer alan işletmeler için ve piyasada faaliyet gösteren bütün yatırımcılar için ekonomik ve finansal analizler yapmak firma performanslarını ön plana sunmak gerektiği noktalarda firmaların eksik yönlerini tespit etmek amacı ile analizler ve uygulamalar yapmak önem arz etmektedir. Çünkü firmaların kalkınması ülke ekonomisinin de kalkınmasının önemli bir unsurudur. Bir işletmenin finansal ve ekonomik yapısının güç kazandığı takdirde ülke ekonomisinin de güç kazanacağ1 bilinmektedir. Bunun için ekonomik ve finansal analizler yapmak önemlidir.

Yukarıda yer alan çalışmada, Borsa İstanbul'da Gayrimenkul yatırım ortakllğı sektöründe faaliyet gösteren ve 2017 yllında sermayesi en yüksek olarak tespit edilen 15 işletmenin verileri ve oranlanı düzenli olan 10 firma tespit edilerek finansal oranları hesaplanmıştır. Finansal oranlar Kap aracıllğ̆1 ile alınan 20132017 dönem sonu finansal tabloları ile hesaplanarak bu finansal oranların ortalaması alınmıştır. Hesaplanan 10 finansal oran ve 10 adet Gyo işletmesi ile karar matrisi oluşturulmuştur. Bu karar matrisi ile çalışmada belirtilen formüller yardımı ile TOPSIS ve MOORA yöntemleri uygulanarak sıralama sonuçları elde edilmiştir. Uygulamada MOORA yönteminde kullanılan 4 ana yaklaşım dikkate alınarak yapılmıştır. 
Yapılan uygulamalar arasında uyum olup olmadığına ve güvenilirliklerine bakılmış, yapılan 5 uygulama arasında da sonuçlarda uyum olduğu gözlemlenmiş ve sonuçların güvenilir olduğu tespit edilmiştir.

Analiz sonuçları neticesinde belirlenen kriterlerde finansal performansı en iyi olarak görülen işletmenin Halk Gyo firması olduğu görülmektedir. İkinci sırada ise yapılan bütün uygulamalarda istikrarlı bir şekilde ikinci sırada yer alan Akiş Gyo işletmesinin yer aldığı görülmektedir. Analiz sonuçlarında üçüncü sırada yer alan işletmelerin farkll1ık gösterdiği gözlemlenmiştir. Sonuç tablosuna göre ise finansal performans açısından kötü olan ve son sırada yer alan işletmelerin sırası ile İş Gyo, Reysaş Gyo ve Özak Gyo işletmeleri olduğu görülmüştür. Yapılan analizler sonucunda belirlenen kriterler bütünüyle bir finansal performansı tespit ettiği söylenemez. Fakat sektörde faaliyet gösteren yöneticilere ve yatırımcılara 1ş1k tutacak bir çalışma olduğu söylenebilir.

Bu çalışma ile Gayrimenkul yatırım ortaklığı sektöründe faaliyet gösteren belirli işletmelerin finansal performansları ortaya konulmaya çalışılmıştır. Elde edilen sonuçlar ile bu sektörde ki şirket yöneticilerine ve yatırım yapmak isteyen birçok yatırımcıya karar almalarında destek sağlayacak veriler sunulduğu düşünülmektedir.

Ayrıca elde edilen bu analizler neticesinde farklı sektörlerde veya aynı sektörde uygulanabilecek diğer analiz yöntemleri ile farklı sonuçlar elde edilebilir ve karşılaştırılma yapılmasına olanak sağlayabilir. Kısacası birçok çalışmaya sşık tutarak yeni bulgular ortaya konulabilecektir.

\section{Kaynakça}

Aktepe A. ve Ersöz S. (2013). Ahp-vvkor ve moora yöntemlerinin depo yeri seçim probleminde uygulanması. Endiistri Mühendisliği Dergisi, 25(1-2), 2-15.

Blaszcynski, J., Greco, S., Slowinski, R. ve Matarazza, B. (2013). JMAF- dominance based rough set data analysis framework user's guide' http://www.cs.put.pozman.pl/jblaszczynski/site/jRS_files/JMAFmanuel.pdf

Blaszcynski, J., Greco, S. ve Slowinski, R. (2007). Multi-criteria classification - A new scheme for application of doominance- based decision rules. European Journal of Operational Research, 181(3), 1030-1044.

Brauers W. K. M. ve Zavadskas E. K. (2006). The MOORA method and its application to privatization in a transition economy. Control and Cybernetics, 35(2), 445-469.

Brauers W. K. M., Ginevicius R., (2009), "Robustness In Regional Development Studies. The case of Lithuania", Journal of Business Economics and Management, 10(2): s:121-140.

Cheng-Ru, W., Chin-Tsai, L. ve Pei-Hsuan, T. (2008). Financial service of wealth management banking: Balanced scorecard approach. Journal of Social Sciences, 4(4), 255-263.

Dumanoğlu, S. (2010). İMKB'de işlem gören çimento şirketlerinin mali performansının topsis yöntemi ile değerlendirilmesi. Marmara Üniversitesi I.I.I.B.F. Dergisi, 29(2), 323-339.

F. Ersöz ve A. Atav, (2011). Çok kriterli karar verme problemlerinde MOORA yöntemi. YAEM Yöneylem Arasstrması ve Endiistri Mühendislig̈i 31.Ulusal Kongresi, Sakarya Üniversitesi, 2011, s. 79.

Fai, L. K., Siew, L. W. ve Hoe, L. W. (2016). Financial analysis on the company performance in malaysia with multicriteria decision making model. Systems Science and Applied Mathematics, 1(1), 1-7.

Karaoğlan, S. (2018). BIST XKMYA işletmelerinin finansal performanslarının çok kriterli karar verme yöntemleri ile ölçümü ve yöntemlerin karşıllaştırlması. Ege Akademik Bakııs Dergisi, 18(1).

Li, H. ve Qing-sheng, X. (2006). Application of TOPSIS in the bidding evaluation of manufacturing enterprises. 5th International Conference on eEngineering \& Digital Enterprise Technology, 16-18 th August, Guiyang, China, 184-188.

Önay, O. ve Çetin, E. (2012). Turistlik yerlerin popülaritesinin belirlenmesi: İstanbul örneği. İ. Ü. İsletme Fakültesi İsletme İktisadi Enstitïsï Yönetim Dergisi, 23(72), 90-109.

Özbek, A. (2015). Akademik birim yöneticilerinin moora yöntemiyle seçilmesi: Kırıkkale üzerine bir uygulama. Kurkkeale Sosyal Bilimler Enstitüsü Dergisi, 38, 1-18.

Özdağoğlu, A. (2014). Normalizasyon yöntemlerinin çok ölçütlü karar verme sürecine etkisi-moora yöntemi incelemesi. Ege Akademik Bakus Dergisi, 14(2), 283-294.

Özdemir, M. (2015). Cok kriterli karar verme yöntemleri. İstanbul: Dora Yayınc1lik.

Pawlakk, Z. (1982). Rough sets. International Journal of Computer \& Information Sciences, 11(5), 341-356.

Qin, X., Huang, G., Chakma, A., Nie, X. ve Lin, Q. (2008). A MCDM-based expert system for climate-change impact assessment and adaptation planning - A case study for the Georgia Basin, Canada. Expert Systems with Applications, 34(3), 2164-2179.

Shih, H. S., Shyur, H. J. ve Lee, E. S. (2007). An extension of TOPSIS for group decision making. Mathematical and Computer Modelling, 45(7-8), 801-813.

Stanujkic, D., Magdalinovic, N., Jovanovic, R. ve Stojanovic, S. (2012). An objective multicriteria approach to optimization using MOORA method and interval grey numbers. Technological and Economic Development of Economy, b,18(2), 331-363.

Tepe, S. ve Görener, A. (2014). Analitik hiyerarşi süreci ve moora yöntemlerinin personel seçiminde uygulanması. İstanbul Ticaret Universitesi Fen Bilimleri Dergisi, 13(25), 1-14. 
Velasquez, M. ve Hester, P. T. (2013). An analysis of multi-criteria decision making methods. International Journal of Operations Research, 10(2), 56-66.

Yıldırım, B. F. ve Önay, O. (2013). BULUT teknolojisi firmalarının bulanık AHP - MOORA yöntemi kullanılarak siralanması. I. Ü. Issletme Fakültesi Issletme İktisadi Enstitüsü Yönetim Dergisi, 24(75).

\section{EXTENDED ABSTRACT}

Companies in the world need to make analyzes in order to make future plans and to maintain their sustainability. Firms give importance to all analyzes made for their development and direct their preferences and project decisions in this way. For this reason, researchers have developed some methods to help companies make decisions and to allow investors to examine financial criteria. These methods can be carried out with many factors in many areas as well as analysis with multi-scale decision making methods. When we look at financial performance analysis, it is seen that ratio analysis is frequently used in addition to comparative statements analysis. However, although ratio ratios obtained with balance sheet items are related to each other, they are not sufficient to explain the financial performance of the company with a certain integrity. It is considered important that ratio ratios are determined by determining certain scales and weights as a whole and it is important to make ratios and financial performance and scale rankings of companies. For this work, multi-criteria decision making methods are frequently used. These methods consist of a number of mathematical methods to find the optimal solution among the alternatives in the specified criteria and scale weights. Although multi-criteria decision making methods incorporate many methods, some methods are used to make financial performance ranking measurements.

Bist real estate investment trust sector in Turkey 'also appears to be important to companies with large shareholders. It is known that it is necessary for companies executives, investors and credit institutions to make financial performance measurements of these companies and to reveal financial situation analyzes. The sector carries the title of reaching the highest values with its capital in BIST. The real estate investment trust sector is a sector that contributes and supports innovation and technology that is developing day by day. It is important to measure the financial performance of such a developing sector group.

In this study, the ten companies with the highest share capital of the companies in the real estate investment trust sector, all of which are listed on Borsa Istanbul, have been identified. In order to ensure that the data of the identified enterprises are smooth and continuous, some prioritized investigations have been made. Ten enterprises with continuous data were identified and analyzes were conducted with these enterprises. The main objective of this study is to determine the best company with the criteria determined by performing financial performance rankings with different status measurement instruments. In addition, two methods of multi - scale decision - making methods were applied frequently and the similarities and statistical similarities of the methods were tried to be determined. In the study, TOPSIS and MOORA methods, which are multi-scale decision making methods, are applied for financial performance rankings.

In the study, ten traditional financial ratio ratios were calculated by using the 2013-2017 year-end financial statements. It was obtained from the Excel package program for the calculation of financial ratios and data from the Public Disclosure Platform for financial data. The structuring of companies within the sector helped to determine these ratios. Single average ratios of the calculated financial ratios were calculated by taking the average of the data obtained for 5 years. The decision matrices of the methods to be applied with the calculated average financial ratios were formed in this way and a decision matrix of $10 * 10$ dimensions was obtained. This same decision matrix was used for TOPSIS and MOORA methods. In the literature, apart from TOPSIS method, 4 different methods are frequently used in MOORA method. In the study, these methods were calculated and examined individually. These methods are as follows: ratio method, reference point approach considering the optimal point, importance coefficient method which gives importance to the weight values of the criteria and the exact product method formed by the multiplication values are included in this study as the methods of MOORA method.

As a result of the results obtained in the study, it was seen that the company which ranked first in four out of five applications was Halk Real Estate Investment Trust. In terms of financial performance ranking, Akiş Gayrimenkul Yatırım Ortaklığ1 is ranked second. In fact, this company was found to be second in all methods applied. This result can be said to be an important factor in ensuring the reliability of applications. In the study, it was observed that the third-ranked enterprises differed according to the 
practices. However, it is determined that the last ranked enterprises are almost the same enterprises. In short, TOPSIS and MOORA methods are similar to each other. Although different methods and mathematical methods, similar results are important for the success of the study and the compatibility of these two methods.

As a result, in order to determine the financial conditions of the real estate investment trust sector, which is one of the biggest sectors in our country, performance and ranking have been tried by using financial ratio analysis and multi criteria decision making methods. Within the scope of the study, some companies have identified the financial performance as the best in the defined scales and some companies have deficiencies, therefore, it has been observed that the financial performance measures are low. In addition, it was found that the applications were consistent with similar results. Finally, it is thought that the study will shed light on different studies in the literature. 